\title{
VIVENCIAS DE ENFERMEIROS NO CUIDADO ÀS PESSOAS EM PROCESSO DE FINITUDE
}

Nurses experiences in caring for people in the process of finitude

Experiencias de enfermeras en el cuidado de personas en el proceso de finitude

Matheus Felipe Gonçalves de Lima Lopes • Enfermeiro pelo Centro Universitário Tabosa de Almeida • E-mail: enfermeiromatheusfelipe@gmail.com

Yasmim Simão Tenorio de Melo • Enfermeira pelo Centro Universitário Tabosa de Almeida • E-mail: 2015106095@app.asces.edu.br

Maria Willyanne Carneiro de Lucena Santos • Enfermeira pelo Centro Universitário Tabosa de Almeida • E-mail: 2015106070@app.asces.edu.br

Diego Augusto Lopes Oliveira - Enfermeiro Mestre em Ciências da Saúde pela Universidade de Pernambuco/UPE • Professor Assistente I do curso de Graduação em Enfermagem Centro Universitário Tabosa de Almeida • E-mail: diegooliveira@asces.edu.br

Ana Maria Sá Barreto Maciel • Psicóloga Mestre em Psicologia Clínica pela Universidade Católica de Pernambuco/UNICAP • Professora assistente no Centro Universitário Tabosa de Almeida • E-mail: anabarreto@app.asces.edu.br

Autor responsável pela correspondência:

Matheus Gonçalves Felipe • E-mail: 2015106101@app.asces.edu.br 


\section{RESUMO}

Introdução: Não há como negar que a morte constitui uma realidade comum nos hospitais, especialmente em setores como Unidades de Terapia Intensiva. Apesar da morte fazer parte do ciclo natural da vida, os profissionais de Enfermagem, geralmente, não são adequadamente preparados para lidar com ela, o que muitas vezes gera sentimentos de sofrimento. Durante a formação acadêmica, o tema morte é pouco abordado e o profissional é incentivado a acreditar que somente a cura e a recuperação do paciente são características de um bom cuidado. Objetivo: Conhecer e explorar as vivências emocionais pregressas dos enfermeiros perante a finitude/morte e o processo de morrer em cuidados intensivos. Método: Estudo exploratório, descritivo de abordagem qualitativa. Utilizou-se como instrumento um roteiro contendo 4 perguntas abertas. Foram entrevistados 10 profissionais enfermeiros que fazem parte do quadro de funcionários da Unidade de Terapia Intensiva de um Hospital do Agreste de Pernambuco. Resultados: Os resultados apontaram que a maior parte dos entrevistados referiu como sentimento negativo a tristeza diante do paciente em finitude, e como sentimento positivo compaixão. A principal dificuldade perante o doente em finitude foi a ausência de protocolos que definem e dão continuidade ao cuidado paliativo. O conforto como objetivo para aliviar a dor e sofrimento foi elencado como principal método para lidar com paciente em finitude. Constatou-se ainda o despreparo dos enfermeiros na graduação perante o processo de morrer. Conclusões: As vivências dos enfermeiros perante a finitude podem causar adoecimento, visto que ainda se predominam sentimentos negativos na assistência, fato que pode ser explicado pela falta de preparação durante a graduação para lidar com a finitude/morte. Ainda há barreiras para implementar o cuidado paliativo nas unidades de terapia intensiva, e associado a isto se tem a falta de compreensão por parte dos profissionais enfermeiros na participação da implementação dos cuidados paliativos.

Palavras-Chave: Enfermagem; Morte; Cuidados Paliativos; Unidades de Terapia Intensiva.

\section{ABSTRACT}

Introduction: There is no denying that death is a common reality in hospitals, especially in sectors such as Intensive Care Units. Although death is part of the natural life cycle, nursing professionals are generally not adequately prepared to deal with it, which often generates feelings of suffering. During the academic training, the subject of death is little addressed and the professional is encouraged to believe that only the cure and recovery of the patient are characteristics of good care. Objective: To know and explore the nurses past emotional experiences in the face of finitude/death and he process of dying in intensive care. Methods: It is an exploratory study, descriptive qualitative approach. A roadmap containing 4 open questions was used as a tool. e interviewed 10 nursing professionals who are part of the staff of the Intensive Care it of a Hospital do Agreste de Pernambuco. Results: The results pointed out that st of the interviewees referred as negative feeling the sadness before the patient in itude, and as positive feeling compassion. The main difficulty facing the finite tient was the absence of protocols that define and provide continuity to palliative 
care. Comfort as an objective to relieve pain and suffering was listed as the main method to deal with patients in finitude. It was also found that nurses were unprepared to die at the time of graduation. Conclusions: Nurses experiences with finitude can cause illness, since negative feelings still prevail in care, which can be explained by the lack of preparation during graduation to deal with finiteness/death. There are still barriers to implement palliative care in intensive care units and associated with this is the lack of understanding on the part of nursing professionals in participating in the implementation of palliative care.

Keywords: Nursing; Death; Palliative Care; Intensive Care Units.

\section{RESUMEN}

Introducción: No se puede negar que la muerte es una realidad común en los hospitales, especialmente en sectores como las Unidades de Cuidados Intensivos (UCI). Aunque la muerte forma parte del ciclo natural de la vida, los profesionales de la enfermería no suelen estar adecuadamente preparados para afrontarla, lo que suele generar sentimientos de sufrimiento. Durante la formación académica, el tema de la muerte se aborda poco y se alienta al profesional a creer que sólo la curación y la recuperación del paciente son características de una buena atención. Objetivo: Conocer y explorar las experiencias emocionales previas de las enfermeras con la finitud/muerte y el proceso de morir en cuidados intensivos. Metodología: Se trata de un estudio exploratorio, descriptivo de un enfoque cualitativo. Se utilizó como instrumento un guión que contenía 4 preguntas abiertas. Entrevistamos a 10 enfermeras que forman parte de la UCI del Hospital do Agreste de Pernambuco. Resultados: Los resultados mostraron que la mayoría de los entrevistados se refirieron como un sentimiento negativo a la tristeza en el cuidado del paciente en finitud. La principal dificultad ante el paciente en finitud era la ausencia de protocolos clínicos de cuidados paliativos. También se observó la falta de preparación de las enfermeras en el proceso de graduación para morir. Conclusiones: Las experiencias de las enfermeras con la finitud pueden causar enfermedades, ya que los sentimientos negativos siguen predominando en los cuidados, lo que puede explicarse por la falta de preparación durante la graduación para hacer frente a la finitud. Todavía existen obstáculos para aplicar los cuidados paliativos en las unidades de cuidados intensivos y, en relación con ello, hay una falta de comprensión por parte de los profesionales de la enfermería para participar en la aplicación de los cuidados paliativos.

Palabras clave: Enfermería; Muerte; Cuidados paliativos; Unidades de cuidados intensivos. 


\section{Introdução}

Refletir sobre a morte é pensar como ensinam as ciências da vida, da saúde e a reflexão filosófica e religiosa, como também nas experiências que se tem sobre esse processo, que envolve a condição de morte, finitude, e vulnerabilidade que fazem parte do ciclo de vida de todo e qualquer ser vivo, que ainda inclui o nascer, o crescer, o decair e o morrer. ${ }^{1}$

A única certeza da vida humana é sem exceções a morte, ela não é apenas uma mera falência física é também uma relação de perda tanto para família quanto para a sociedade em geral. A interferência dos sentimentos diante da proximidade da morte é a mais diversa, se dá desde os de caráter negativo como fracasso, impotência, silêncio, ódio, dentre outros; até os de caráter positivos, como paz, celebração da própria vida, do valor da pessoa em vida, além dos inspirados em concepções divinas. Assim, é através destes sentimentos que o indivíduo busca significados de sua existência, onde se depara com a ideia de finitude. ${ }^{2}$

A falta de inclusão da finitude humana e a ausência da reflexão no aperfeiçoamento emocional no projeto de vida de cada um presumem o despreparo do profissional da saúde quando reduz a experiência da morte do outro apenas à finalização de um processo de tratamento médico. Esse comportamento dos profissionais da saúde fundamenta-se em um entendimento de enfrentamento, que tem como característica desconsiderar a morte como "acontecimento" e, dessa maneira, apreciar como um fenômeno que ultrapassa a forma das explicações científicas. ${ }^{3}$

É frequente a exposição dos profissionais de saúde em situações de enfrentamento da morte dos pacientes sob seus cuidados, mas, apesar desse confronto cotidiano na sua vivência de trabalho, esses profissionais ainda encontram dificuldades de encará-la como parte integrante da vida e rotina de serviços, onsiderando esse processo como o resultado do fracasso da assistência prestada. ${ }^{4}$

Os profissionais enfermeiros constantemente vivenciam a condição do fracasso assistência prestada, fato que mobiliza o cuidado às pessoas na sua finitude, 
experimentando sentimentos conflitantes de maneira mais intensa, tornando-se um tema recorrente de estudo, enfocando a situação de morte nas diversas fases do ciclo vital e suas implicações no ambiente de trabalho. ${ }^{4}$

O cuidar além da busca da cura envolve o saber lidar tanto com a morte daquele paciente em estado crítico, com os familiares e com si próprio, que cotidianamente se depara com a morte ${ }^{5}$, principalmente nos setores hospitalares onde a vivência da morte acontece de forma mais frequente.

Este estudo procurou entender como a vivência do cuidado a pessoas em condição de finitude pode interferir no equilíbrio emocional dos enfermeiros de unidades de terapia intensiva, visto que enfermeiros são os profissionais da equipe que permanecem mais horas com o paciente e constantemente vivenciam a realidade dos pacientes e familiares, as angústias e sofrimentos. Portanto diante dessas emoções e sentimentos que os profissionais da enfermagem são passíveis de vivenciar, identificam a morte como um processo inerente à vida, mas não conseguem ser inertes aos sentimentos que permeiam esse evento. ${ }^{6}$

O objetivo foi conhecer e explorar as vivências emocionais pregressas dos enfermeiros perante a finitude/morte e o processo de morrer em cuidados intensivos. Diante das características apresentadas, esse estudo surgiu a partir do interesse perante a vivência dentro do hospital e a proximidade com os pacientes acometidos em processo de finitude, nas dificuldades enfrentadas pelo enfermeiro em lidar com esses pacientes e o desafio na sua prática do cuidado.

\section{Metodologia}

Trata-se de um estudo exploratório, descritivo de abordagem qualitativa. A abordagem qualitativa é utilizada para a obtenção de dados subjetivos relacionados universo dos significados, dos motivos, das aspirações, das crenças, dos valores, s atitudes. Esse agrupamento de fenômenos humanos é entendido como parte da lidade social, pois possibilita o ser humano não só agir, mas também a pensar sobre le faz e a interpretar suas ações, a partir da realidade vivida e partilhada. ${ }^{7}$ 


\section{ciência
piural}

O estudo foi realizado na Unidade de Terapia Intensiva de um Hospital do Agreste de Pernambuco, região nordeste do Brasil, voltado para o atendimento de emergência, sendo referência em trauma (traumato-ortopedia, cirurgia geral e bucomaxilo-facial) de alta complexidade, tendo em sua estrutura bloco cirúrgico, leitos de UTI, sala de recuperação pós-anestésica e o Núcleo de Reabilitação Física.

Incluíram-se profissionais enfermeiros acima de 18 anos que trabalham e que lidam com pacientes em processo de finitude/morte da Unidade de Terapia Intensiva de um Hospital do Agreste de Pernambuco; excluíram-se enfermeiros que estão atuando há menos de 1 ano na UTI.

Inicialmente os enfermeiros da unidade de terapia intensiva que fariam parte da pesquisa seriam 22, porém 1 se recusou a participar, dois estavam de férias, e, devido a trocas de plantões, faltas e outros trabalharem fora do horário da coleta de dados, a amostra da pesquisa resultou em 10 profissionais enfermeiros que fazem parte do quadro de funcionários da Unidade de Terapia Intensiva do HRA.

A coleta dos dados foi realizada pelos autores do estudo em uma única sessão e aconteceu no período de março a abril de 2019. Para avaliarmos as respostas e encontrarmos se os participantes teriam alguma dificuldade em responder as perguntas, foram realizadas, com auxílio da orientadora experiente em pesquisas qualitativas, 5 entrevistas com professores enfermeiros na universidade onde os autores cursavam a graduação em enfermagem, na qual foi reformulada uma pergunta no instrumento de coleta.

A abordagem dos profissionais se precedeu na apresentação do TCLE e explanações sobre os objetivos, os aspectos metodológicos e a finalidade do estudo. A coleta de dados foi realizada em local reservado, na própria unidade de saúde, pela tarde, uma vez que os profissionais relataram que nesse período seria viável para participar da entrevista. Utilizou-se como instrumento um roteiro contendo 4 rguntas abertas, em que as respostas foram gravadas, com autorização dos ticipantes, e posteriormente foram transcritas e associadas à literatura para análise. empo médio das entrevistas foi de 7 minutos e 30 segundos. 
Para análise de dados foi empreendida uma análise das falas, orientada pela perspectiva da análise de conteúdo de Bardin, em que todas as entrevistas foram transcritas e analisadas minuciosamente. As entrevistas foram registradas em gravador digital e transcritas preservando a fidedignidades das informações colhidas, as entrevistas serão armazenadas em um pen drive, onde ficarão arquivadas por 5 anos após o término da pesquisa, tendo sob responsabilidade dos pesquisadores.

A análise organiza-se em torno de três momentos: pré-análise, que consiste na transcrição das conversas gravadas, na leitura flutuante dos conteúdos e na retomada do contexto dos objetivos do estudo; exploração do material, que consiste na operação de codificação, com a constituição do corpus a partir da transformação dos dados brutos; e o recorte do texto em unidades de registro (a frase). ${ }^{8}$

O estudo cumpriu as exigências éticas de acordo com a Resolução do Conselho Nacional de Saúde de no 510/2016 cabíveis aos estudos com seres, sendo submetido e aprovado pelo Comitê de Ética em Pesquisa sob o protocolo $\mathrm{n}^{\mathrm{o}}$ 3.211.895. Todos os participantes concordaram e assinaram o termo de consentimento livre esclarecido (TCLE). O anonimato dos pacientes foi preservado a partir da utilização da codificação “E” para enfermeiro(a), seguido do número referente à ordem da entrevista.

\section{Resultados e Discussão}

Do total de participantes, 9 eram do sexo feminino e 1 do sexo masculino. A faixa etária variou de 24 a 52 anos. Quanto à titulação, dos 10 participantes 7 têm pósgraduação em UTI, 1 apenas graduação, 1 pós em obstetrícia e 1 em psicologia positiva. O tempo de formação variou de um ano e meio a 29 anos (média de sete anos e três meses). No período da coleta de dados, os 10 enfermeiros estavam atuando em UTI adulto.

Para atender os objetivos propostos desta pesquisa, que tem como base identificar as vivências dos enfermeiros no cuidado ao paciente em processo de initude/morte em UTI e após a análise temática dos dez entrevistados, emergiram as guintes categorias: “Sensações e Sentimentos mobilizados diante do cuidado aos cientes em condição de finitude ou morte" na qual surgiram 2 subcategorias, de ter negativo e de caráter positivo; "Dificuldades encontradas no cuidado ao doente 
em condição de finitude/morte"; “Estratégias utilizadas para lidar com pacientes em finitude/morte"; "Preparação dos enfermeiros durante a graduação para lidar com pacientes em processo de finitude/morte".

Sensações e Sentimentos mobilizados diante do cuidado ao paciente em condição de finitude ou morte

As sensações e sentimentos foram desde as de caráter positivo até as de caráter negativo, foram perceptíveis, diante das falas e demonstração de gestos, as dificuldades em refletir sobre esta categoria em relação ao paciente em condição de finitude/morte. As sensações e sentimentos que mais se prevalecem foram de caráter negativo: Tristeza, e de caráter positivo: Compaixão, identificadas através das seguintes falas:

\section{De Caráter negativo:}

[...] No que diz respeito às emoções, eu sinto tristeza porque às vezes a gente acaba se apegando ao paciente que está em cuidados paliativos [...] (E1).

[...] Dependendo também de pacientes a gente sente tristeza, por exemplo, já tive paciente aqui que morreu que era um adolescente [...] então realmente é uma tristeza que a gente sente [...] (E2).

[...] É mais a questão de você ficar triste por saber que aquele paciente não vai ter um prognóstico bom, e você só pode aliviar com cuidados paliativos. Até porque tem muitos que não sabem administrar esse sentimento e acaba adoecendo também de alguma forma (E7).

Tristeza, claro! Quando a gente chega e recebe a notícia que "Ah esse paciente está em paliação, então esse paciente infelizmente não vai poder investir porque não tem probabilidade de melhora", [...] (E8)

Os enfermeiros são considerados profissionais para servir, cuidar e, para que se aça jus a estas atribuições, é necessário que aconteça o envolvimento emocional, a mpatia, e desta forma surge o vínculo entre profissional-paciente-família, o que de 
forma inconsciente poderá levá-lo a sentir-se impotente em algumas situações e abatido emocionalmente. ${ }^{9}$

Lidar continuamente com pacientes não faz o enfermeiro mais preparado para manejar seus sentimentos, emoções e ideias expressas pelos pacientes e familiares, uma explicação para isso se deve à preparação insuficiente e do envolvimento emocional que pode ser considerado quase que impossível não acontecer e desta forma ocasionar consequências negativas para a assistência, como o sofrimento. ${ }^{9}$

Prestar assistência a pacientes sem possibilidade de cura, pode gerar diversos sentimentos capazes de desgastar emocionalmente o profissional. Podemos perceber através dos relatos dos enfermeiros que em sua grande maioria referiu tristeza, sentimento mais comum para se expressar diante de um acontecimento que propicie insatisfação.

O sentimento de tristeza constitui uma resposta universal frente às situações que representem perda, derrota, desapontamento entre outras dificuldades da vida humana. No que concerne a isto, essas respostas cumpre um valor adaptativo, uma vez que, através do retraimento, poupa energia e recursos para o futuro. Em contrapartida, constitui-se como um sinal de alerta, para os que presenciam a tristeza do outro, indicando que a pessoa que vivencia essa tristeza está precisando, principalmente de ajuda. ${ }^{10}$

Como o profissional enfermeiro está constantemente lidando com a finitude e vivenciando a morte dos seus pacientes, a sensação de tristeza está presente constantemente, sob grande valor nos enfermeiros do estudo que prestam assistência na UTI. O sentimento de tristeza é um dos sintomas da depressão, e que esta sensação precisa ser persistente. É sabido que, para se afastar de uma vivência que causa tristeza, é preciso se desvincular daquele que o causa, ou saber encontrar maneiras para lidar com ela. ${ }^{10}$ Porém o profissional enfermeiro não pode se distanciar de um paciente e não se envolver emocionalmente, mesmo que o tente. Torna-se notória esta firmação diante das entrevistas do presente estudo.

Diante das escassas pesquisas que buscam avaliar a depressão entre alhadores de enfermagem em UTI, é mencionado com unanimidade que as 
exposições constantes a diversas situações em relação a eventos estressores dentro da UTI podem estar associadas ao aumento da prevalência de depressão nos enfermeiros desta unidade hospitalar, sobretudo aqueles que exercem suas atividades em UTIs gerais, retomando mais uma vez aos enfermeiros do estudo em questão. ${ }^{11}$

De caráter positivo:

Muitas vezes o sentimento é de compaixão[...] Ver um paciente sofrendo tanto e você já fez tudo que podia e não tem mais o que fazer [...] Mas você sabe que está fazendo o seu melhor dentro das condições que você tem (E6)

O sentimento é de mais de compaixão [...] Por saber que tem o paciente que está em processo de finitude, que está num fim, e que necessita de todo apoio, de todo cuidado possível (E9)

Uma das características da Enfermagem é lidar constantemente de sentimentos e emoções, tanto do próprio profissional, quanto do seu paciente, que surge de forma inevitável, como consequência do cuidado. Todo cuidado é movido pela emoção, fato perceptível quando identificamos nas entrevistas que, por mais que seja difícil vivenciar a finitude e a morte dos pacientes, os enfermeiros tendem a sentir compaixão como forma do dever cumprido, diante do paciente que não consegue mais atender as medidas de curabilidade. ${ }^{12}$

Um dos elementos da compaixão é a humanidade, elemento essencial na assistência de pacientes que estão em paliação. ${ }^{13,14}$ Nota-se, diante do presente estudo, que na assistência o sentimento de compaixão ele é presente, é um forte ponto positivo, pois revela o respeito e compreensão sobre o paciente que está no fim. Exercer a compaixão não é fácil, obriga-nos a transcender as fronteiras da tradição e das diferenças e sugere que qualquer sentido de diferenciação entre as pessoas deve ser emovido.

Quando o enfermeiro trabalha com a compaixão e com a intenção de aliviar o imento, ocorre troca de energia entre paciente-profissional. Quando há uma 
interação entre duas pessoas em um relacionamento como no ambiente hospitalar, desenvolve-se uma interação dos seus campos de energia, cada um se torna o ambiente do outro. E ainda o profissional compassivo transborda uma energia de compaixão que o leva a se entregar no cuidado, deixando de lado o seu ego, que o leva a interiorizar, conhecer, aliviar ou eliminar o seu sofrimento, fazendo entender que o paciente necessita de cuidados, e que esse cuidado não visa a cura, e que de certa forma leva o enfermeiro a pensar na ideia de finitude e principalmente refletir como processo natural da vida. ${ }^{15}$

\section{Dificuldades encontradas no cuidado ao doente em condição de finitude/morte}

As dificuldades enfrentadas perpassam desde as do próprio hospital, equipe multiprofissional e em relação aos familiares. Porém foram perceptíveis, em sua grande maioria, as dificuldades encontradas no que diz respeito ao enfermeiro se reconhecer como membro relevante da equipe multiprofissional na implementação e continuidade dos cuidados paliativos. Observou-se como a falta de comunicação entre a equipe e a falta de protocolos facilitam a implementação do cuidado paliativo. Podemos perceber através das seguintes falas:

[...] O médico de hoje chega e fala em paliar um paciente e aí a gente começa a paliar o paciente, a equipe oferta medidas de conforto, analgesia e amanhã chega um médico e diz "Nós não vamos paliar essa paciente, nós vamos investir nesse paciente". Então assim, eu acho que a maior dificuldade em realmente saber quando paliar o paciente é a conduta médica $[. .].(E 1)$

[...] A dificuldade que a gente tem é nessa definição de até onde ir, de até onde investir no paciente [...] Não se tem instituído esse protocolo de paliação, não existe essa comissão de paliação e a gente precisaria de uma definição a respeito disso [...] (E4)

Pela minha visão como profissional seria a instituição de protocolos, que infelizmente a instituição ela não tem esses protocolos instituídos, então cada plantão, cada médico ele tem uma conduta diferente [...] (E9) 


\section{[...] A principal dificuldade são as condutas profissionais com relação à}

os médicos entrarem em próprio consenso, sobre o paciente em condição de finitude [...] De implementar protocolos, algo mais concreto, não só ficar com o de boca a boca [...] (E10)

O cuidado paliativo é destinado ao paciente crítico desde a sua admissão até nas situações em que não são mais aplicáveis medidas de curabilidade, que tem como objetivo proporcionar o bem-estar visando a uma morte digna e tranquila para o doente em finitude, independente do setor hospitalar no qual este paciente esteja inserido. Esta forma de cuidar deve envolver todos da equipe multiprofissional atuantes na UTI, inclusive os enfermeiros da pesquisa, que, junto ao paciente e à família, devem identificar os procedimentos desnecessários e estabelecer ações paliativas necessárias. ${ }^{16}$

Em cuidados paliativos é relevante pensar na associação de toda a equipe multiprofissional, uma vez que diversos profissionais atuam na unidade de terapia intensiva do presente estudo. Pensar dessa forma influencia positivamente a assistência prestada, levando estes profissionais ao entendimento fundamental das decisões pertinentes ao paciente, priorizando seu conforto e qualidade de vida. ${ }^{17}$

A equipe de enfermagem em sua prática assistencial tem se destacado como profissionais importantes em cuidados paliativos, uma vez que atuam como um elo entre o paciente, os demais profissionais e os familiares. Assim a compreensão e participação dos profissionais desta pesquisa sobre as modalidades de cuidados paliativos é fundamental para o direcionamento no plano de cuidados, bem como na execução de ações paliativas no contexto da terapia intensiva. ${ }^{17}$

Um estudo realizado com 14 profissionais de saúde, incluindo 6 enfermeiros, de uma unidade de terapia intensiva, observou que o grande obstáculo para o desenvolvimento dos cuidados paliativos na UTI é o despreparo da equipe multiprofissional em indicar a abordagem paliativa, além de muitas dúvidas em ação à continuidade da terapia de cuidados paliativos. Concluiu-se que é de trema importância a criação de protocolos assistenciais, com a finalidade de 
direcionar os cuidados a serem executados, buscando amenizar o sofrimento do paciente em finitude e de sua família, promovendo uma morte digna e tranquila. ${ }^{17}$

Associado aos dilemas discutidos anteriormente, existe com grande notoriedade nas falas dos entrevistados a falta de comunicação, sobre discussões pertinentes às condutas a serem tomadas em relação ao paciente. A comunicação eficaz entre a equipe multiprofissional, o paciente e seus familiares interferem no estado do indivíduo, pois ajuda a orientar, apoiar, esclarecer e, também, a auxiliar na execução de suas necessidades humanas básicas, evitando constrangimentos e perda de autonomia profissional diante no cuidado ao doente em finitude. ${ }^{16}$

Estratégias utilizadas para lidar com pacientes em finitude/ morte

Refletir sobre essas estratégias foi um desafio para os enfermeiros. Uma explicação para esta dificuldade poderia ser os questionamentos poucos frequentes sobre esta temática, ou mesmo por nunca terem percebido algo na sua assistência que seria estratégico para lidar com os pacientes em processo de finitude/morte.

Apesar de ser uma categoria mais pessoal e a possibilidade de cada um ter uma forma diferente de lidar com os pacientes em processo de finitude/morte, foram obtidas respostas semelhantes, como, por exemplo, proporcionar o conforto como uma forma de propiciar um cuidado que pudesse amenizar o fato do paciente está na condição de finitude e desta forma se sentir bem. A sensação de proporcionar algo que possibilite a ideia de liberdade daquela condição pode amenizar de alguma forma o desconforto dos profissionais de enfermagem diante destas vivências, identificados nos seguintes argumentos:

A estratégia que eu utilizo é sempre tentar fazer com que o paciente ele se sinta confortável. Um paciente que está em cuidados paliativos não é um paciente que vai morrer e a gente não precisa mais fazer nada [...] Eu acho que o paciente em cuidados paliativos ele deve ter toda e qualquer assistência, desde medidas de conforto como analgesia, como carinhos, massagens e conversas (E1) 


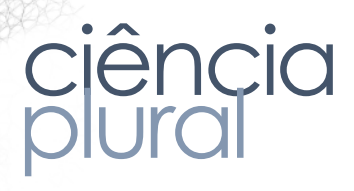

[...] Eu tento fazer o máximo que eu posso pelo paciente, deixá-lo o mais confortável possível para sair com aquela sensação de pelo menos dever cumprido, que você deu o que podia dar ao paciente [...] (E3)

[...] Eu procuro pensar no conforto do paciente, eu sei que é sofrido, eu sei que a gente vê muito sofrimento tanto por parte do paciente como da família, mas eu busco fazer o melhor que eu posso [...] (E5)

A estratégia que eu utilizo para lidar com o paciente em paliação é melhorar o conforto e dessa maneira eu me sinto melhor diante (E8)

Diante destas falas, é notório que estes profissionais deixam claro o respeito pelo paciente, ao incorporar na sua prática comprometimento em proteger o paciente diante da sua vulnerabilidade, através do cuidado, visto que o cuidado paliativo começa quando não há mais propósito de cura. Atitudes como as dos enfermeiros da pesquisa tornam ameno o sofrimento e dão conforto ao paciente.

Segundo definição da Organização Mundial de Saúde (OMS), "Cuidado Paliativo é uma abordagem que promove a qualidade de vida de pacientes e seus familiares, que enfrentam doenças que ameacem a continuidade da vida, através da prevenção e alívio do sofrimento". ${ }^{18}$

Quando se refere ao Cuidar em Enfermagem esta definição da OMS se consolida como essencial na prática do enfermeiro e este como agente principal na atuação do paciente sem medidas de curabilidade. O cuidar, no âmbito da enfermagem, consiste em envidar esforços para o outro, visando a proteger, promover e preservar, ajudando pessoas a encontrar significados na doença, sofrimento e dor, bem como da sua existência. Tem como premissa essencial a tentativa de evitar que o outro sofra, ou que, ao identificar este sofrer, realiza medidas para erradicar ou minimizar o sofrimento. ${ }^{19}$

Ao analisar estas definições, associa-se o cuidado paliativo com o cuidar da fermagem como indissociáveis e complementares e ainda se percebe o quão valiosa torna a prática baseada no respeito e comprometimento do paciente sem sibilidade terapêutica. Percebe-se nas entrevistas que melhorar o conforto através práticas baseadas em evidências científicas é importante, as quais acabam 
reforçando a assistência e direcionando o cuidado, de forma a atender o diferente na sua diferença, o que resgata um princípio do SUS, a equidade, aspecto valioso e desejável principalmente na assistência de cuidados paliativos.

Preparação dos enfermeiros durante a graduação para lidar com pacientes em processo de finitude/morte

Preparar os estudantes para o enfrentamento da temática finitude/morte é uma tarefa bastante difícil, porém foi possível observar que vem se debatendo sobre este assunto, porém de forma superficial e em tempo reduzido, podendo-se perceber através das falas a seguir:

[...] Eu quase não tive esse tema dentro da graduação, com exceção de uma cadeira optativa que foram duas aulas só. A gente quase não falou dessa questão de finitude na graduação [...] (E6)

Que eu me lembre na graduação a gente não vê muito não sobre essa questão dessa preparação, eu acho que deveria ser melhor abordado também até por questão de saúde tanto psicológica quanto mental dos profissionais. (E7)

Foi um aspecto muito geral e muito superficial, eu acredito que deveria ser mais debatido esse assunto enquanto graduação (E10)

Percebe-se diante da literatura que as Instituições de Ensino Superior ainda são metódicas quanto ao ensino voltado apenas à patologia, desconsiderando a individualidade de cada ser humano. Reafirma-se esta evidência quando nas entrevistas o tema finitude/morte foi pouco abordado ou de forma muito superficial durante a graduação destes profissionais, e que pouco prepararam para a realidade hospitalar e principalmente quando associamos com as outras categorias do estudo.

Durante a formação acadêmica do enfermeiro, o tema da morte e do morrer é pouco abordado. Persiste nos cursos de graduação dos profissionais de saúde uma fase excessiva na cura, que não raro passa a ser considerada como finalidade única tratamento, associada à crença contemporânea na eficácia onipotente da tecnologia última geração. Assim, os profissionais vão se sentindo comprometidos usivamente com a vida, e é para a preservação desta que se sentem capacitados. 
Os enfermeiros, já no primeiro ano do curso de graduação, durante as aulas de anatomia, são levados a lidar com a morte pela via da negação, por meio da despersonalização do paciente, que é significado como cadáver, órgãos e tecidos desvitalizados. Esse prelúdio define os próximos movimentos, enquadrando a formação em saúde como um fazer tecnicista destituído de valores humanitários. 20,21,22

Dar prioridade a discussões sobre práticas curativas, de certa forma, desprepara o profissional para o inevitável que seria justamente o processo de finitude ou a morte, e que ocasiona momentos de conflitos com si próprio. Isso expõe o profissional com formas de enfrentamento insuficientes diante desta situação, visto que refletir com ênfase nos processos finais da vida e dar valor a essas discussões fortalecem o estudante e os deixam mais preparados para a assistência.

\section{Conclusões}

Percebe-se que, diante do estudo, prevalece o mesmo sentimento negativo de tristeza, perante a assistência ao paciente sem possibilidade terapêutica. É comum dentro das UTI que este sentimento associado a outros fatores desgastantes podem levar o profissional ao adoecimento, e que a depressão é uma ocorrência frequente. Através dos relatos dos enfermeiros, evidencia-se que esta pesquisa serviu mais como um desabafo, do que como uma simples resposta de uma pesquisa científica. Falar assuntos pouco discutidos para estes profissionais foi bastante relevante.

Mesmo obtendo respostas com sentimentos negativos, destacou-se o sentimento de compaixão, que pode servir como ensinamento para novas formas de sentir e se envolver com o paciente em finitude, visto que sentir compaixão está ligada às objeções do que concerne os cuidados paliativos.

Os resultados deste estudo demonstraram a falta de autonomia dos enfermeiros no que diz respeito a sua inserção nas tomadas de decisões do paciente que necessita de cuidados paliativos. Deste modo, destaca-se a importância de desenvolver estudos área que evidenciem e deem credibilidade ao profissional enfermeiro nas tomadas decisões relacionadas ao indivíduo sem possibilidade terapêutica. 
Além do estabelecimento de protocolos que definem a paliação como facilitação do manejo de pacientes em cuidados paliativos, a implementação de educação permanente sobre esses cuidados e capacitação para os profissionais se revelam como uma ação eficaz, diante da falta de conhecimento sobre a importância de considerar a equipe multiprofissional como imprescindível no cuidado a estes pacientes. Portanto, desenvolver ações que potencializem o cuidado a estes pacientes, dá significado ao cuidado paliativo e ainda possibilita aos profissionais reverem sua prática, pautada em cuidados dessa natureza.

Todas as categorias do estudo mostraram a importância em se debater sobre finitude/morte, visto que sentimentos negativos e as dificuldades em lidar com a temática podem ser trabalhadas na graduação, para ajudar o profissional a entender este processo como uma forma natural e saber enfrentar com mais aptidão estas situações complexas.

As limitações do estudo é que foi realizado em apenas um hospital, uma vez que as mudanças de horários constantes dos enfermeiros sem aviso prévio impediram que a amostra se tornasse maior.

\section{Referências}

1. Schramm FR. Morte e finitude em nossa sociedade: Implicações no ensino dos cuidados paliativos. RevBras Cancerologia. 2002; 48(1): 17-20. [Acesso em: 01 maio 2019]. Disponível em: http://www1.inca.gov.br/rbc/n_48/v01/pdf/opiniao.pdf

2. Silva C, Alencar S, Lacerda MR, Centa ML. Finitude humana e enfermagem: reflexões sobre o (des) cuidado integral e humanizado ao paciente e seus familiares durante o processo de morrer. Rev Fam. Saúde Desenv. Curitiba, v.7, n.2, p.171-180, maio/ago. 2005. [Acesso em: 01 maio 2019]. Disponível em: https://revistas.ufpr.br/refased/article/download/8045/5668

Nogueira ACC, Oliveira LM, Pimentel V. O profissional da saúde e a finitude humana a negação da morte no cotidiano profissional da assistência hospitalar. Rev irt Textos \& Contextos, $n^{\circ}$ 6, dez. 2006. [Acesso em: 01 maio 2019]. Disponível em: ttp://revistaseletronicas.pucrs.br/ojs/index.php/fass/article/viewFile/1026/806

Bellato R, Araújo AP, Ferreira HF, Rodrigues, PF. A abordagem do processo do rrer e da morte feita por docentes em um curso de graduação em enfermagem. Rev Paul Enferm. 2007; 20(3): 255-63. [Acesso em: 01 maio 2019]. Disponível em: :/ / www.scielo.br/pdf/ape/v20n3/a03v20n3.pdf 
5. Silva RS, Campos AER, Pereira A. Cuidando do paciente no processo de morte na Unidade de Terapia Intensiva. RevEscEnferm USP. 2011; 45(3):738-44. [Acesso em: 01 maio 2019]. Disponível em:

http://www.scielo.br/pdf/reeusp/v45n3/v45n3a27.pdf

6. Silveira NR, Nascimento ERP, Rosa LM, Jung W, Martins SR, Fontes MS. Cuidado paliativo e enfermeiros de terapia intensiva: sentimentos que ficam. RevBrasEnferm UFRN. 2016;69(6):1074-81. [Acesso em: 10 fevereiro de 2020]. Disponível em: http://www.scielo.br/pdf/reben/v69n6/0034-7167-reben-69-061074.pdf.

7. Minayo MCS. O desafio do conhecimento: pesquisa qualitativa em saúde. $14^{\text {a }}$ ed. São Paulo: HUCITEC; 2014.

8. $\quad$ Bardin L. Análise de Conteúdo. 5a ed. Lisboa: Edições 70; 2009.

9. Kolhs M, Machrib E, Ferrib G, BrustolinA ;Boccac M. Sentimentos de enfermeiros frente ao paciente oncológico. J Health Sci 2016;18(4):245-50. [Acesso em: 03 maio 2019]. Disponível em:http:/ / fi-admin.bvsalud.org/document/view/47sb6

10. Porto JAD. Conceito e diagnóstico. RevBras Psiquiatr. Depressão - vol. 21 - maio 1999. [Acesso em: 03 maio 2019]. Disponível em: http://www.scielo.br/pdf/rbp/v21s1/v21s1a03.pdf

11. Vargas D, Dias APV. Prevalência de depressão em trabalhadores de enfermagem de Unidade de Terapia Intensiva: estudo em hospitais de uma cidade do noroeste do Estado São Paulo. Rev. Latino-Am. Enfermagem set.-out. 2011;19(5): 1-9. [Acesso em: 03 maio 2019]. Disponível em: http://www.scielo.br/pdf/rlae/v19n5/pt_08.pdf

12. Santos MLSC, Padilha MICS. As posturas compassivas na enfermagem - o sofrimento que permeia o cuidar. Rev. Bras. Enferm. Brasilia, 2002 Set/ Out. 55 (5); 542-548. [Acesso em: 03 maio 2019]. Disponível em: http://www.scielo.br/pdf/reben/v55n5/v55n5a10.pdf

13. Neff, Kristin. The Development and Validation of a Scale to Measure SelfCompassion. Self and Identity, 200; 2(3).

14. Pommier, Elizabeth. Development of a Scale to measure compassion. Austin: University of Texas, 2010.

Dunn, Dorothy J. A Way of Knowing, Being, Valuing and Living with mpassion Energy: A Unitary Science and Nursing as Caring Perspective. Visions: e Journal of Rogerain Science, 2009; 16(1): 36-47.

Souza HLR, Lacerda LCA, Lira GG. Significado de cuidados paliativos pela ipe multiprofissional da unidade de terapia intensiva. Rer. enferm UFPE online, 
2017, Recife,11(10):3885-92. [Acesso em: 01 maio 2019]. Disponível em: https:// periodicos.ufpe.br/revistas/revistaenfermagem/article/view/109102/2432 7

17. Luiz MM, Netto JJM, Vasconcelos AKB, Brito MCC Cuidados paliativos em enfermagem ao idoso em UTI: uma revisão integrativa. Rev. Cuidado é fundamental online 2018. 10(2): 585-592. [Acesso em: 01 maio 2019]. Disponível em: http://www.seer.unirio.br/index.php/cuidadofundamental/article/view/5051/pd f_1

18. Academia Nacional de Cuidados Paliativos (ANCP). Manual de Cuidados Paliativos, 2012 [Acesso em: 03 maio 2019]. Disponível em:

http://biblioteca.cofen.gov.br/wp-content/uploads/2017/05/Manual-de-cuidadospaliativos-ANCP.pdf.

19. Beserra EP, Oliveira FC, Ramos IC, Moreira RVO, Alves MDS, Braga VAB. Sofrimento humano e cuidado de enfermagem: múltiplas visões. Escola Anna Nery. Rev Enferm,2014 Jan-Mar 18(1). [Acesso em: 03 maio 2019]. Disponível em: http://www.scielo.br/pdf/ean/v18n1/1414-8145-ean-18-01-0175.pdf

20. Kovács MJ. Educação para a morte: desafio na formação de profissionais de saúde e educação. $1^{\text {a }}$ ed. São Paulo: Casa do Psicólogo; Fapesp, 2003.

21. Oliveira JR, Brêtas JRS, Yamaguti L. A morte e o morrer segundo representações de estudantes de enfermagem. Rer. Esc. Enferm USP 2007;41(3):386-394. [Acesso em: 10 Junho 2019] Disponível em: http://www.scielo.br/pdf/reeusp/v41n3/07.pdf

22. Nascimento $C A D$, Silva $A B$, Silva $M C$, Pereira MHM. A significação do óbito hospitalar para enfermeiros e médicos. Rer. RENE 2006;7(1):52-60. [Acesso em: 20 Junho 2019] Disponível em:

http://www.periodicos.ufc.br/rene/article/view/5369/3928

Submetido em 24/03/2020

Aceito em 11/06/2020 